\title{
Advances in the Assessment of Buildings Sub- jected to Earthquakes and Tsunami
}

Tiziana Rossetto,

Professor in Earthquake Engineering

EPICentre, Dept. of Civil, Environmental and Geomatic Engineering,

University College London,

Gower Street, London, WC1E 6BT

Tel: +44 (0)2076794488

e-mail: t.rossetto@ucl.ac.uk

Crescenzo Petrone,

Earthquake Research Analyst,

Willis Towers Watson,

51 Lime Street, London, EC3M 7DQ

e-mail: Crescenzo.Petrone@WillisTowersWatson.com

Ian Eames,

Professor in Fluid Mechanics

EPICentre, Dept. of Mechanical Engineering,

University College London,

Gower Street, London, WC1E 6BT

e-mail: $\underline{\text { i.eames@ucl.ac.uk }}$

Camilo De La Barra,

EPICentre, Dept. of Civil, Environmental and Geomatic Engineering,

University College London,

Gower Street, London, WC1E 6BT

e-mail: camilo.bustamante.16@ucl.ac.uk

Andrew Foster,

Lecturer

School of Mechanical, Aerospace and Civil Engineering,

University of Manchester,

Manchester, M13 9PL

e-mail: andrew.foster-3@manchester.ac.uk

Joshua Macabuag

NatCat and Research and Development Analyst

SCOR,

10 Lime St, London, EC3M 7AA

e-mail:macabuag@googlemail.com 


\begin{abstract}
Currently, 8 out of the 10 most populous megacities in the world are vulnerable to severe earthquake damage, while 6 out of 10 are at risk of being severely affected by tsunami. To mitigate ground shaking and tsunami risks for coastal communities, reliable tools for assessing the effects of these hazards on coastal structures are needed. Methods for assessing the seismic performance of buildings and infrastructure are well established, allowing for seismic risk assessments to be performed with some degree of confidence. In the case of tsunami, structural assessment methodologies are much less developed. This stems partly from a general lack of understanding of tsunami inundation processes and flow interaction with the built environment. This chapter brings together novel numerical and experimental work being carried out at UCL EPICentre and highlights advances made in defining tsunami loads for use in structural analysis, and in the assessment of buildings for tsunami loads. The results of this work, however, demonstrate a conflict in the design targets for seismic versus tsunami-resistant structures, which raise questions on how to provide appropriate building resilience in coastal areas subjected to both these hazards. The Chapter therefore concludes by summarizing studies carried out to assess building response under successive earthquakes and tsunami that are starting to address this question.
\end{abstract}

\title{
1.0 Introduction
}

Currently, 8 out of the 10 most populous megacities in the world are vulnerable to severe earthquake damage, while 6 out of 10 are at risk of being severely affected by tsunami, (Sundermann et al. 2014). In order to mitigate ground shaking and tsunami risks for coastal communities, there is first a need to understand and quantify these risks. As a significant portion of the economic and life losses sustained in natural hazards stem directly or indirectly from damage to the built environment, two fundamental components of risk assessment are the characterization of hazardinduced actions on buildings and their response to these actions.

Seismic hazard analysis is an established field of study with many tools widely available for both probabilistic and scenario strong ground motion assessments, which allow the actions on structures from earthquakes to be evaluated with some confidence. The literature also presents significant advances in the modelling of earthquake-triggered tsunami hazards (e.g. Goda et al. 2017, Suppasri et al. 2016), with tsunami transformations into coastal margins being well-modelled by existing numerical codes (e.g. MOST by Titov and Synolakis 1998 and FUNWAVE by Grilli et al. 2007, amongst others). These numerical models are able to simulate offshore wave characteristics of tsunami wave forms, however modelling of the flow inundation depths and velocities as the tsunami travels onshore remains a challenge. The latter is highly complex and requires the use of very high bathymetric and topographic resolutions for the numerical models to provide a realistic simula- 
tion of the flow (e.g. as seen in Mader 2004). Furthermore, the computational expense required to explicitly model the presence of coastal buildings on the tsunami inundation means that it is almost never done in practice; the effect of the built environment on the tsunami flow more commonly modelled through the use of an increased onshore bed roughness. This means that the vast majority of existing tsunami onshore inundation numerical models and simulations are unable to provide a direct evaluation of tsunami forces on buildings. Instead, these have to be calculated from empirical or semi-empirical equations that relate tsunami force to the flow characteristics that can be predicted by these models, e.g. from the inundation depth, $h$, velocity, $u$. Such force equations can be found in current and past tsunami design guidance documents (e.g. Okada et al. 2006, FEMA 2008, ASCE7-16 2017), but show limited consensus. Due to limited observational data on tsunami, the empirical closures of the presented force equations are based either on expert opinion or on experiments; the latter being very limited in their representation of realistic tsunami, (see Section 2.0).

Similarly to the case of seismic hazards, methods for assessing the seismic performance of both individual and classes of buildings are well established. Several approaches for the numerical analysis of structural response to earthquakes exist, which range in computational expense from more burdensome non-linear response history analyses of complex structural models to rapid non-linear static-based analyses of highly simplified structural models. Consequently, seismic fragility functions exist for buildings that are based on numerical analysis (e.g. see compendium presented in Yepes-Estrada et al. 2016 as an example). A fragility function relates the probability that a building (or building class) will reach or exceed a number of pre-defined damage states when subjected to increasing hazard actions. Fragility functions provide a concise overview of structural performance under the natural hazard and hence are commonly used in natural catastrophe risk modelling.

In the case of tsunami, structural assessment methodologies are much less developed, with very few analysis-based fragility functions existing in the literature. The lack of literature in this field relates partly to the aforementioned general lack of understanding of tsunami inundation processes and flow interaction with the built environment. However, recent advances in the physical modelling of tsunami in the laboratory (see Rossetto et al. 2011) are helping to shed light on this field and opening opportunities to significantly progress the field of structural analysis for tsunami.

This Chapter presents a concise summary of the journey the authors have taken over the last 5 years to start to answer some of the structural engineering questions that still pose a significant challenge in the study of building response to tsunami:

1. What are the tsunami forces on buildings?

2. How do we analyse buildings for tsunami loads?

3. What is the role of ductility on structural response to tsunami?

4. How can we best analyse a structure under sequential earthquake and tsunami loads? 
The work presented in this chapter is part of a larger programme of research being conducted by University College London and HR Wallingford in the European Research Council funded URBANWAVES project, which has also significantly advanced the understanding of tsunami onshore flows through innovative large scale experiments and computational fluid dynamics.

\subsection{What are the tsunami forces on buildings?}

The first author first began to look at the issue of tsunami forces on buildings after returning from a field reconnaissance of the 2004 Indian Ocean Tsunami (Rossetto et al. 2007), with the idea that tsunami inundation loads on buildings have a strong horizontal component, and that if this loading could be appropriately characterized, similar techniques to those used in earthquake engineering could be used to assess structural response to tsunami.

Guidance documents for the design of tsunami-resistant structures at the time, treated tsunami loading as a severe flood. Most adopted a tsunami force formulation composed of three components (e.g. FEMA 2005): hydrostatic force (dependent on flow depth, $d$ ), hydrodynamic force (dependent on onshore flow velocity, $v$ ) and impulse load (initial overshoot associated with the impact of the leading tongue of a wave or surge). Only peak forces were designed for, with the time dependence of tsunami forces on the buildings being completely ignored.

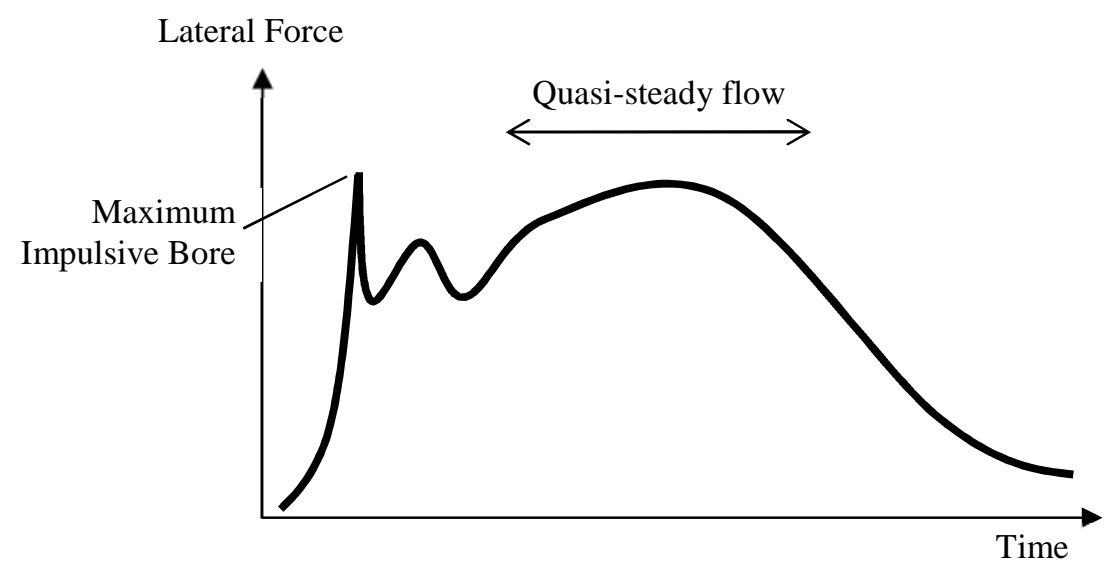

Figure 1: Illustration of general tsunami loading history on an onshore structure

Despite knowledge that loads from tsunami inundation can be of long duration due the typical wave periods of tsunami (20-40mins), see Figure 1, the time-dependent nature of tsunami loading is also ignored in the later published FEMA P646 guidelines (FEMA 2008) and current ASCE-16 (2017) code. One of the reasons 
for this is that all these guidelines are based on experiments that use relatively shortperiod waves and highly idealized waveforms to represent tsunami.

Most worldwide facilities adopt piston wave-makers, which simply do not have the stroke length to generate realistic tsunami wavelengths at the scale necessary to reproduce its physical processes. Such facilities are typically limited to the generation of solitary waves with periods $<10$ s (i.e. prototype tsunami wave period of approximately $2 \mathrm{mins}$, assuming scale of 1:50), and have great difficulty in reproducing stable trough-led waves that can characterise tsunami. Through a collaboration between UCL and HR Wallingford, in 2008 a new type of pneumatic tsunami generator was developed (Rossetto et al. 2011), which underwent several improvements over the following 6 years as described in Allsop et al (2014) and Chandler et al. (2016). This new tsunami generation system, when operated in a long flume equipped with a sloping bathymetry, allowed, for the first time, the study of tsunami forces on onshore buildings subjected to extremely long waves of different waveform (i.e. both elevated and trough-led waves).

Foster et al. (2017) presents the results of one such series of experiments wherein impermeable rectangular model buildings of different widths, $b$, (representing different blockage ratios, $b / w$, with respect to the flume width, $w$ ), are subjected to both crest- and trough-led waves of periods ranging between 20-240s at 1:50 scale (i.e. up to 20minute tsunami prototype). The following key observations are made in this study:

1. For the long waves adopted, for blockage ratios less than 1.0, no initial impulse loading is detected (see Figure 2).

2. Tsunami waves with periods exceeding 80 s produce quasi-steady flows (see Figure 3).

3. There is a local influence, due to the presence of the obstacle in the flow, which results in higher blocking ratios introducing greater unsteadiness (see Figure 3).

These observations brought the authors to propose a modification to the steady-flow force equations proposed in Qi et al. (2014) for representing the measured tsunami loads on buildings. 


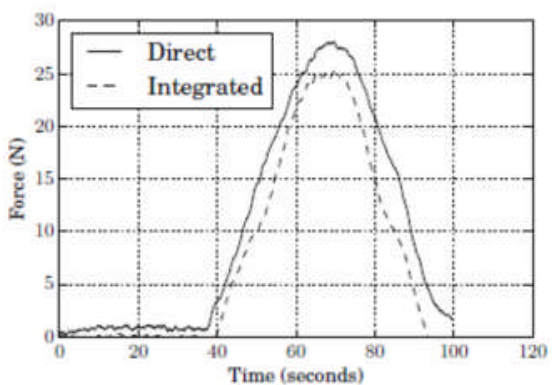

(a)

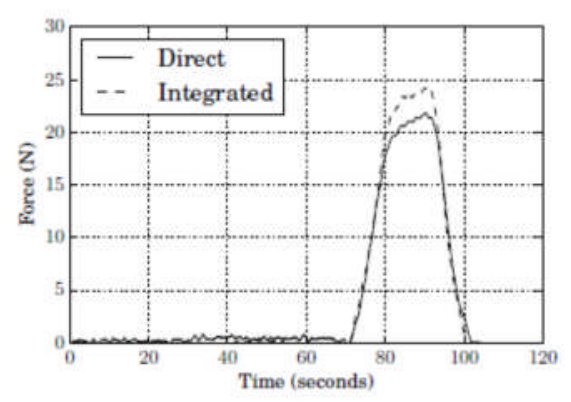

(b)

Figure 2: Sample tsunami inundation force time histories measured at the model building, (blockage ratio 0.6), by Foster et al. (2017) for (a) an elevated wave with 80 s period and (b) trough-led wave with 80 s period. The full lines show the measured force obtained from the load cells and the dashed line, the force obtained by integrating the pressures measured at the pressure transducers.

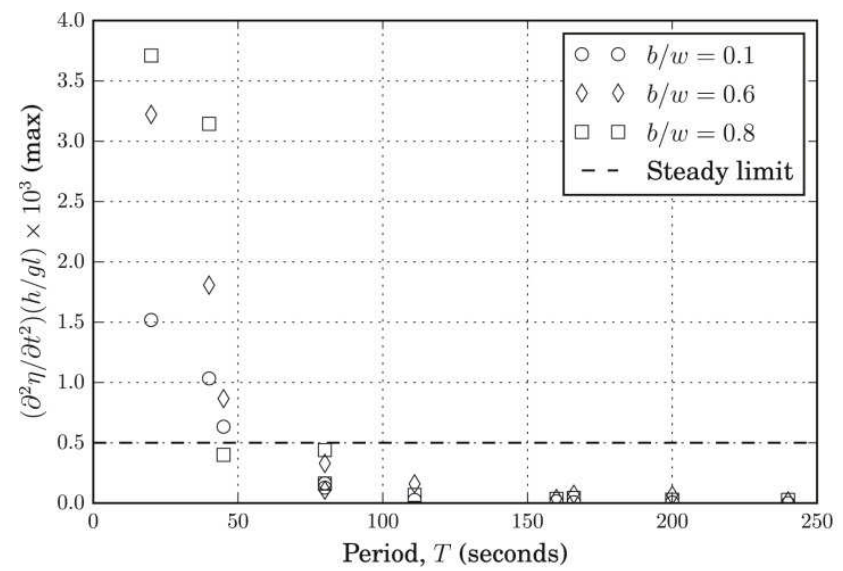

Figure 3: Plot showing the degree of steadiness with respect to the wave period, T. The flow is considered unsteady when $\frac{\delta^{2} h}{\delta t^{2}}$ is greater than $0.05 \%$ of the quantity $(h / g l)$, which corresponds to a term that can adequately non-dimensionalise the water depth time derivative whilst also encompassing the influence of the length,

$l$, of the obstacle in the flow. Figure modified from Foster et al. (2017).

From tests conducted in a small scale laboratory at UCL, Qi et al (2014) showed that steady flows around rectangular bodies were subcritical for low incident flow Froude numbers $\left(F r_{l}\right)$, inducing drag-dominated forces on the structure. However, when the incident Froude number reached or exceeded a critical value $\left(F r_{c}\right)$, the flow transitioned to a choked state, where hydrostatic forces dominated (Figure 4). They also showed that the value of $F r_{c}$ was affected by the blocking ratio of the 
body with respect to the flume $(b / w)$. Finally, by proposing a relationship between the incident and downstream Froude numbers, Qi et al. (2014) proposed simple equations for the estimation of the overall force on the rectangular body that could be evaluated solely from knowledge of the incident flow depth $\left(h_{l}\right)$, velocity $\left(u_{1}\right)$ and the blockage ratio.

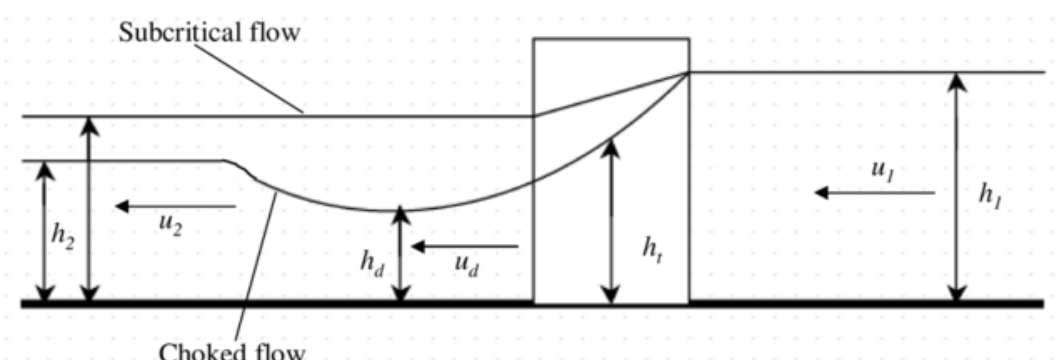

Figure 4: Schematic diagram of the subcritical and choked flow conditions around a rectangular body, redrawn from Qi et al. 2014. In the figure the subscript 1 refers to the incident flow parameters, subscripts $d$ and 2 to the flow parameters immediately and far downstream of the rectangular body, respectively.

In the context of tsunami onshore flow numerical modelling, where as stated in Section 1.0, the presence of the buildings is not explicitly modelled, the force formulations of Qi et al. (2014) formed a viable empirical closure for force calculation that, as opposed to other equations, accounted for the state of the flow around the building. Hence, in Foster et al. (2017) the formulae were updated and modified to better fit the large scale tsunami experimental data, and were extended to the characterization of tsunami forces from unsteady inundation flows (associated with the shorter tsunami waves). These result in Equations 1 and 2 for steady flows, i.e. when $\left(\frac{\delta^{2} h}{\delta t^{2}}\right)\left(\frac{h}{g l}\right)<0.0005$, where 1 is the length of the building:

$F_{T}=\frac{1}{2} C_{D} \rho b u_{1}^{2} h_{1} \quad$ for $\quad F_{R 1}<F_{R c}$ (subcritical conditions)

$F_{T}=\lambda_{s} b g^{1 / 3} u_{1}^{4 / 3} h_{1}^{4 / 3}$ for $\quad F_{R 1} \geq F_{R c}$ (choked conditions)

where, $\lambda_{s}=0.73+1.2(b / w)+1.1(b / w)^{2}$

Instead Equations 1 and 4 result for unsteady flows, i.e. when $\left(\frac{\delta^{2} h}{\delta t^{2}}\right)\left(\frac{h}{g l}\right) \geq 0.0005$ :

$F_{T}=\lambda \mathrm{bg}^{1 / 3} u_{1}^{4 / 3} h_{1}^{4 / 3}$ for $F_{R 1} \geq F_{R c}$ (choked conditions)

where, $\lambda=1.37-1.35(b / w)+1.37(b / w)^{2}$ 
A further important observation made is that irrespective of the flow conditions, the pressure distribution along the front of the structure follows a triangular (hydrostatic) distribution.

\subsection{How do we analyse buildings for tsunami loads?}

Current guidelines for the design and assessment of buildings under tsunami actions do not contain specific guidance as to how to apply the tsunami loads to the building for the structural analysis nor which analysis methods to use for the structural response assessment. Having developed a means to better evaluate both the tsunami loading on buildings and the imposed pressure distribution, we began to investigate how best to analyse coastal buildings for tsunami loading. A summary of this investigation to date is presented in Petrone et al. (2017). In this paper, a case study structure is used to compare the tsunami response parameters predicted by three different analysis approaches, and collapse fragility functions are built.

The case study structure used is a Japanese 10-storey reinforced concrete moment resisting frame vertical evacuation structure. The structure is designed to resist both earthquake and tsunami actions, and the reader is referred to the paper for full details of the model structure. The building is evaluated using the existing non-linear constant-height pushover approach (CHPO) used in Attary et al. (2017), amongst others. For the first time, the paper also assesses the building using tsunami non-linear response history analysis (TDY) and the newly proposed variable height pushover analysis (VHPO).

TDY follows the same principles as a seismic response history analysis, except that, in this case, the tsunami force time history $\left(F_{T}(t)\right)$ is applied to the structure using a triangular load distribution up to the tsunami inundation height at the relevant time step, and the resulting structural deformations are measured. For their application Petrone et al. (2017) adopt the steady state force formulations of Qi et al. (2014) to derive over $800 F_{T}(t)$ from tsunami inundation height $(h(t))$ and velocity $(u(t))$ time histories calculated by Goda et al. (2016) for the 2011 Tohoku earthquake and tsunami.

The CHPO method is an approach that is similar to a conventional earthquake pushover analysis, but modified to account for the characteristics of tsunami loading. In CHPO a constant inundation depth $(h)$ is considered, and a displacementcontrolled analysis is carried applying the lateral load to the structure according to a hydrostatic-type distribution. As the inundation height is constant, the force is increased by increasing the velocity of the inundation flow, thus changing the Froude number (Fr) as the analysis progresses.

The non-linear variable height pushover analysis (VHPO) differs from CHPO as it applies lateral loads to the structure according to a hydrostatic-type distribution, however it linearly increase the inundation depth up to a target value, $h_{\max }$, whilst maintaining a constant Froude number. VHPO is a force-controlled procedure, and its disadvantage is that it is unable to capture the post-peak behaviour in the pushover curve. 
The three procedures are used to assess the collapse of the structure. For the pushover analyses, the structure is assumed to be failed when the tsunami peak force exceeds the structural strength; the structural strength is assessed as the peak force in the pushover curve. This definition of collapse implicitly assumes that ductility does not play a role in the structural assessment. In the case of TDY collapse is predicted to occur when the structure exhibits an inter-storey drift ratio (IDR) equal to that which occurs when the structure reaches peak strength in the pushover analysis. Such a collapse criterion is consistent with that defined for the pushover.

Comparison of the structure response and collapse prediction obtained using TDY, CHPO and VHPO results in the following main observations:

1. The tsunami response of the structure is sensitive to the load discretization used to apply the lateral loads. Ideally the tsunami load should be distributed along the height of the structure with five or more load application points per storey.

2. VHPO approximates well the engineering demand parameters and collapse fragility curves obtained from TDY for a wide range of tsunami time-histories.

3. The VHPO outperforms CHPO in predicting the maximum IDR and column shear at the ground storey (see Figure 5).

4. Neither pushover-based approach can predict the structural response if there is a strong second peak in the tsunami inundation time history (see Figure 5)

5. The tsunami peak force is better correlated to the maximum IDR than flow velocity and inundation depth, and results in fragility curves with lower dispersion values.

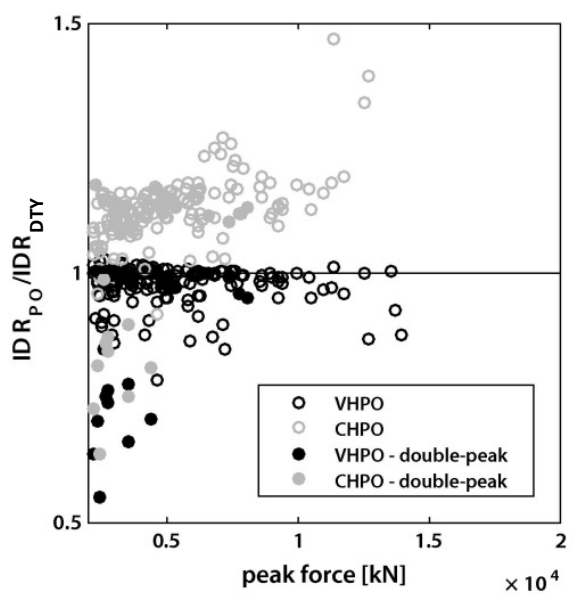

(a)

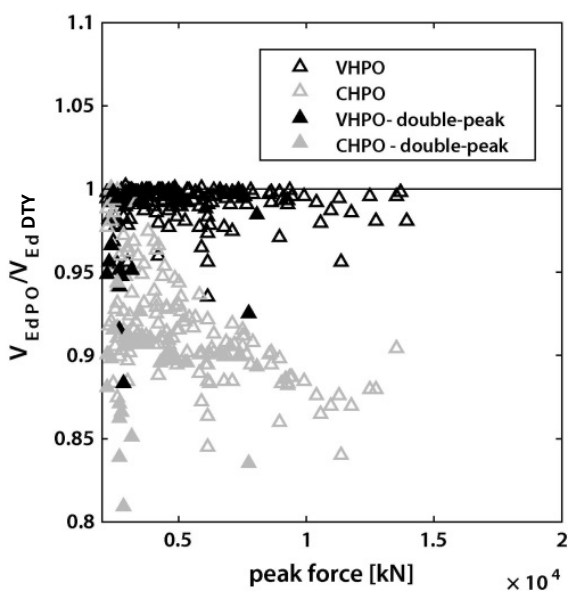

(b)

Figure 5: Comparison of IDR and shear demand (VEd) for CHPO and VHPO versus DTY. Double-peak wave cases are shown with filled markers. Adapted from

Petrone et al. (2017). 
The tsunami applies significant shear forces and concentrated deformations at the bottom storeys of the building. To the collapse point, the static pushover approaches (particularly VHPO) provide a very good estimate of the structure response under TDY, suggesting that the loading does not significantly excite the structural dynamics. However, an explicit decision was made to ignore the contribution of ductility to the structure response. In the case of the Japanese evacuation building this assumption is justified by the fact that, despite being designed for earthquake and tsunami actions, column shear failure precipitates collapse before the maximum strength of the structure is reached. However, if this shear failure was avoided, what role would the building ductility play in the structural response to tsunami?

\subsection{What is the role of ductility on structural response to tsunami?}

To answer this question we went back to fundamental structural dynamics concepts. As a structure deforms under a time-dependent load, it develops inertia forces, damping forces and internal (spring) forces. By solving the equation of motion, it can be shown analytically (see Rossetto et al. 2018b) for an elastically perfectly plastic (EPP) single degree of freedom system of mass $m$, and stiffness $k$, that the plastic displacement ductility demand $\left(\mu_{p}\right)$ is a function of the applied load, the yield force, $F y$, and the natural period of the structure, $\mathrm{T}\left(2 \pi \sqrt{\frac{m}{k}}\right)$. In Rossetto et al. (2018b) the duration over which a structure can sustain a load greater than its yield load $\left(t_{p}\right)$ is calculated for a two idealized tsunami load histories: a triangular and parabolic load history. The analytical results are then verified numerically, before extending the analysis to consider structural damping, strain-hardening and realistic tsunami loading profiles.

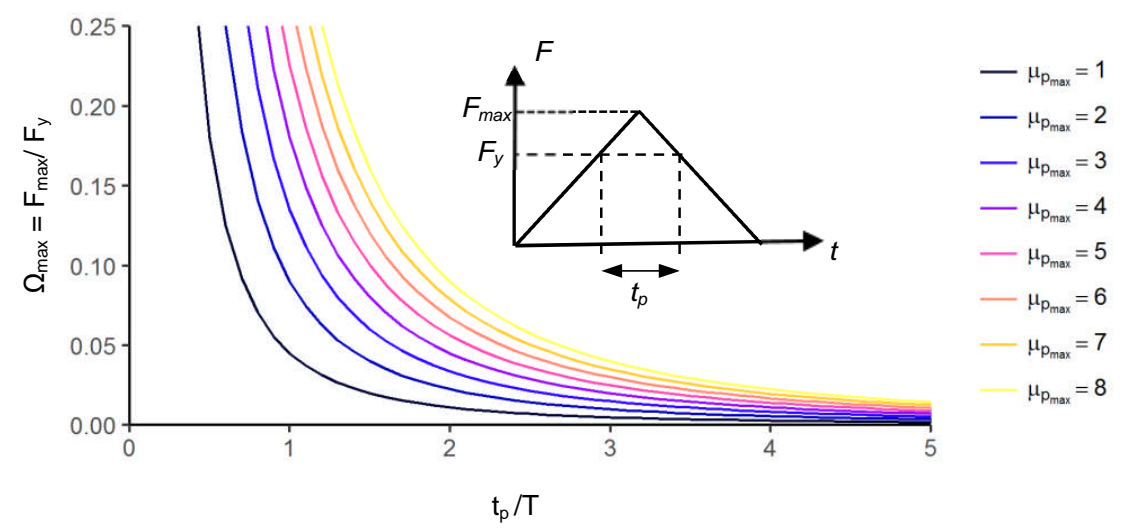

Figure 6: Relationship between the calculated maximum overstrength $\left(\Omega_{\max }\right)$ and $t_{p} / T$ for different ductility values. Modified from Rossetto et al. (2018b). 
Figure 6 presents the results for the EPP SDoF subjected to the triangular loading history. The figure shows the relationship between the calculated maximum overstrength $\left(\Omega_{\max }\right)$ and $t_{p} / T$. It is observed that an increase in structural ductility corresponds to a higher achievable overstrength, but that overstrength values greater than $5 \%$ can only be achieved if the time over which the force applied to the structure exceeds yield is less than 1 to 2.5 times the structure natural period. Translating this into practical numbers, if we consider a 10 storey reinforced concrete moment resisting frame with a natural period of around 1s and ductility of 4.0, this would achieve negligible overstrength for any duration of plastic loading $\left(t_{p}\right)$ exceeding $3.5 \mathrm{~s}$. If we consider that strong tsunami inundations can exceed minutes in duration, it becomes clear that structural ductility cannot be relied upon to allow the structure to sustain loads exceeding its yield capacity. Rossetto et al. (2018b) show that the inclusion of strain hardening in the SDoF can improve the achievable overstrength. However, again, for realistic values of strain hardening this increase in overstrength is negligible.

The results of this study indicate that in order to achieve tsunami resistance, a structure needs to be designed to resist the full tsunami loading elastically. This can be extremely expensive if the structure does not allow the tsunami inundation to flow through it (relieving pressures on external walls and structural elements). As the structural strength, rather than its deformation capacity, governs the tsunami resistance of the building, and given the steady nature of tsunami inundation flows, this study reinforces the suitability of pushover-based analysis methods for the assessment of buildings under tsunami.

\subsection{How can we best analyse a structure under sequential earth- quake and tsunami loads?}

As maximum strength is found to govern the tsunami design of buildings (Section 4.0), in areas at risk from both seismic excitation and tsunami inundation, the effect on the tsunami response of damage to the structure in a preceding earthquake should be considered.

Only two existing studies have been found that have looked into the tsunami response of structures previously damaged by earthquake ground shaking through numerical techniques. Park et al. (2012) and Latcharote and Kai (2014) both adopt non-linear response history analysis for assessing their structural models under the earthquake loading, and follow this with a constant height pushover (CHPO) for the tsunami response assessment. Both adopt a coarse discretisation of the applied tsunami loading along the height of the building for the CHPO, which is shown by Petrone et al. (2017) to significantly affect the reliability of the tsunami pushover analysis results. CHPO is also shown to provide an over-prediction of the tsunami induced shear forces and displacement response at the building's lower storeys. Neither of the existing studies have compared their overall structural response against an earthquake and tsunami non-linear response history analysis. Equally, none have 
attempted to look at the possibility of simplifying the earthquake analysis phase, through use of an earthquake pushover (PO).

In Rossetto et al. (2018a), we systematically change the analysis approach used in each of the three phases involved in the assessment of structural behavior under sequential earthquakes and tsunami, namely the earthquake loading phase, unloading of the structure until at-rest condition and the tsunami loading phase. In the earthquake loading phase non-linear response history analysis (DY) was considered as well as a static nonlinear pushover (PO) with a typical lateral load distribution following the shape of the first mode response of the structure (e.g. FEMA, 2000). Two types of unloading analyses were considered. However, these were seen to have little effect on the final earthquake and tsunami response of the building, and hence are not reported here. In the tsunami loading phase, tsunami nonlinear response history analysis (TDY), constant height pushover (CHPO) and variable height pushover (VHPO) were considered. For both pushover analyses, the performance point (P.P. in Figure 7) is determined at the point of intersection between the tsunami pushover curve and a horizontal line representing the tsunami force demand, $F_{T}$. As in Petrone et al. (2017), the structure is assumed to be collapsed if the tsunami demand is larger than the structural lateral load capacity. This definition of collapse relies on the fact that ductility has been proven to not to play a significant role in the tsunami performance of buildings (Rossetto et al. 2018b).

All combinations of earthquake, unloading and tsunami analysis approaches were implemented for the response assessment of the same Japanese evacuation building used in Petrone et al. (2017) and previously discussed in Section 3.0. The results of the earthquake and tsunami non-linear response history analysis combination (DY-TDY) were used as the reference against which to measure the reliability and accuracy of the other earthquake and tsunami analysis method combinations. Sixteen of the $800+$ simulated earthquake ground motion and tsunami inundation time-history pairs of Goda et al. (2016) for the 2011 Tohoku earthquake and tsunami were selected to run the reference case. These were chosen to cover a range of earthquake and tsunami intensities.

For brevity, in this section only the main results of the comparison of DY-TDY with DY-VHPO and PO-VHPO are presented. The reader is referred to Rossetto et al. (2018a) for the complete comparison of approaches and the sensitivity analyses performed. It is highlighted that the double pushover approach (PO-VHPO), illustrated schematically in Figure 7, presents significant computational savings as compared to DY-TDY. PO-CHPO is still faster to run, however, this is seen to come at the significant expense of accuracy, and this analysis combination is not recommended for use in sequential earthquake and tsunami analysis.

Several engineering response parameters (ERP) such as inter-storey drift ratios at each floor (IDR), top displacements, base shear, internal forces and floor accelerations can be measured across the analyses. However, in the case of the earthquake pushover, the analysis needs to be stopped at a desired point (i.e. point B in Error! Not a valid bookmark self-reference.) before the subsequent unloading and tsunami loading is applied. The analyst can choose where to stop the earthquake 
PO analysis, for example, when a specific damage state is achieved in the structure (associated with the occurrence of a specific value for the measured ERPs). Else, a capacity spectrum based method, (for instance, FRACAS as described in Rossetto et al. 2016), can be used to determine the structure performance point under a given earthquake ground motion or spectrum.

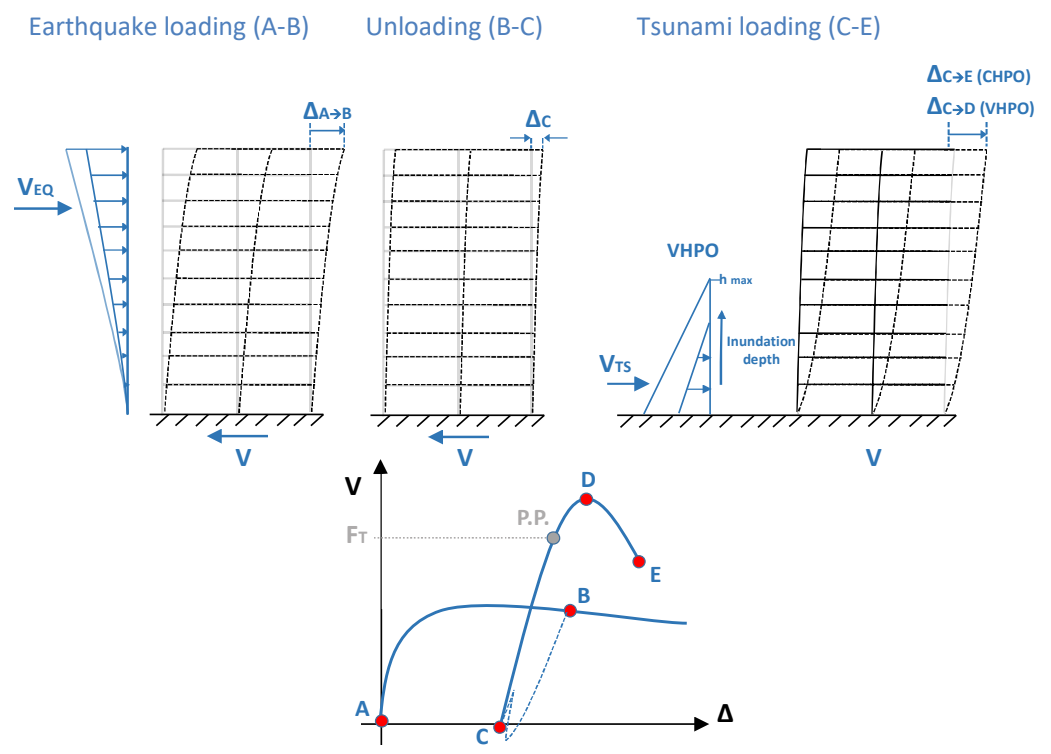

Figure 7. Schematic representation of the double pushover methodology for the PO-VHPO case.

However, in order to eliminate the effect of estimation errors in the earthquake performance point arising from, for instance, the use of a capacity spectrum based assessment, Rossetto et al. (2018a) decided to stop the PO analysis when the maximum inter-storey drift ratio experienced by the structure in the corresponding DY analysis $\left(I D R_{\max , D Y}\right)$ was achieved in a matching floor within the structure subjected to the PO analysis. It is acknowledged that this matching procedure can lead to different estimates of the overall damage distribution on the structure (with the exception of the matched floor), as the response under dynamic excitation differs from the one under static pushover.

Figure presents a comparison of the global and storey-level response of the case study structure when analysed using combinations DY-TDY, DY-VHPO and POVHPO for two selected earthquake-tsunami pairs of moderately high earthquake intensity and varying tsunami intensities. It is clear that, when compared with the reference DY-TDY case, DY-VHPO shows an excellent agreement in terms of the global behaviour and IDR distribution. On the other hand, the change in the analysis type for the earthquake phase from DY to PO, yields a worse estimate of the global displacements (Figure 8c) and IDR distribution (Figure 8d). 


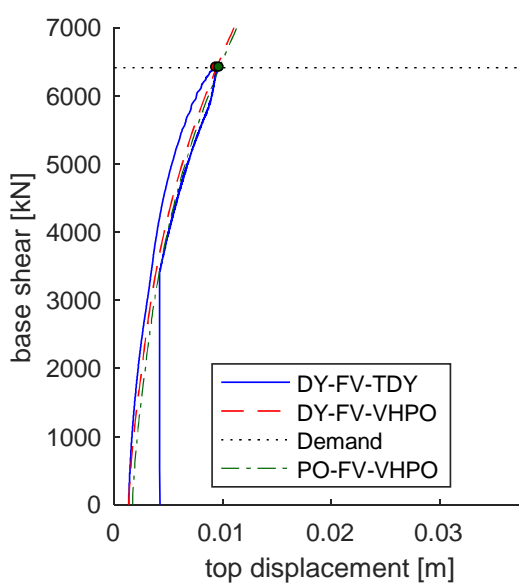

a)

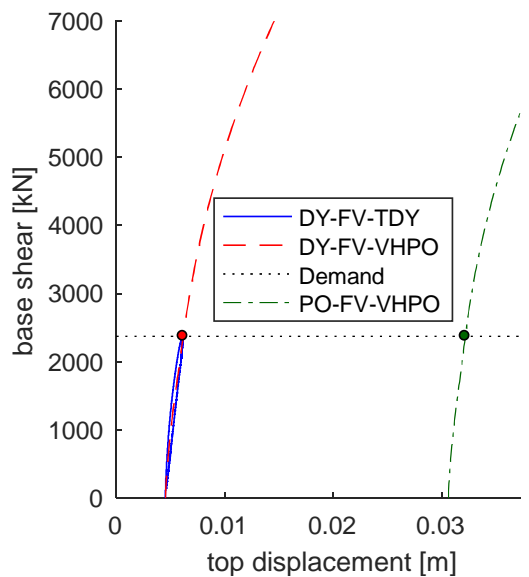

c)

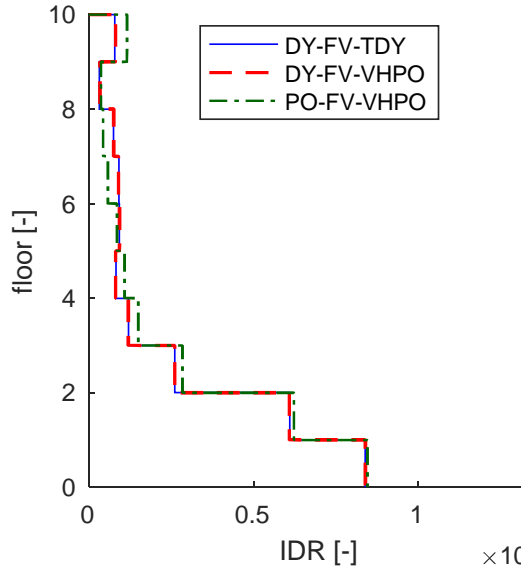

b)

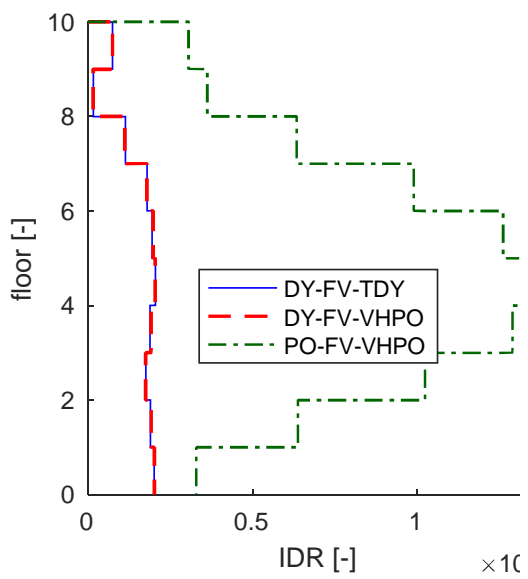

d)

Figure 8. Comparison of tsunami global response (a and c) and IDR distribution (b and d) for two different earthquake-tsunami pairs.

The reason for this behaviour is that for the second earthquake-tsunami pair (Figure 8Figure c-d), under the earthquake loading phase for the PO analysis, the structure is pushed to a large value of $I D R_{\max }(0.670 \%)$, resulting in a significant residual displacement after the structure unloading phase. This in turn, results in the observable shift along the $\mathrm{x}$-axis of the reloading tsunami VHPO curve in Figure 8c. Such a large residual displacement is not observed in the corresponding DY-VHPO case. Furthermore, in this particular case, as the tsunami intensity is relatively low, the tsunami pushover does not significantly modify the residual IDR profile resulting from the earthquake PO analysis. Hence, the final IDR profile in the PO- VHPO 
analysis is significantly different from the reference DY-TDY case. This observation is repeated for all the cases where the earthquake pushover has induced significant plasticity in the structure, and the subsequent tsunami has a relatively low intensity.

Despite the observed differences in displacement and IDR response when the earthquake PO is used instead of the DY analysis, PO-VHPO predicts quite well the shear internal force in the most critical column of the structure, (at the tsunami performance point, Figure 9) for the 16 cases assessed. This is explained as the shear internal force at the ground storey of the building is driven by the tsunami loading; observation which is sustained by the lack of difference in shear internal force values when the earthquake analysis type is changed, whilst a visible difference in shear internal force results when the tsunami analysis is changed from CHPO to VHPO.

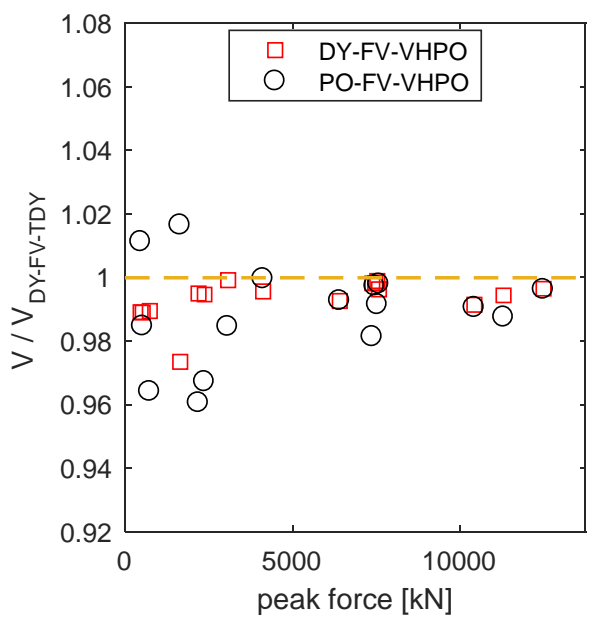

Figure 9. Error in shear force estimation in the most critical column at the end of all three loading phases.

These results suggest that DY-VHPO could be used as an alternative to DY-TDY for the analysis of important or critical infrastructure. This approach provides good accuracy, a reduced computational time, and, as it adopts a pushover-based tsunami assessment, the same analysis can be used to assess the earthquake damaged structure under numerous subsequent tsunami events.

Furthermore, despite the observed discrepancies in the IDR and displacement responses predicted by DY-TDY and PO-VHPO, the latter double pushover approach does provide reasonable estimates of the shear internal forces. The performance of this approach could also be improved if applied to buildings that are predominantly dominated by a first mode response, as it is expected that the difference in the structure deformed shape between DY and PO for these would be less. Due to the fact that in Section 4.0 we see that the tsunami response of a structure is inherently strength-based (with the ductility playing a secondary role), the double 
pushover method might be suitable for use in fragility assessments of populations of buildings, where a significant saving in computational expense might justify the loss in accuracy of response prediction. For such cases, the use of a capacity spectrum based approach for the estimation of the structure performance under the earthquake loading phase would provide acceptable results.

\subsection{Conclusions}

Over the last 10 years experimental capabilities for simulating tsunami have evolved and are allowing the study of ever more realistic tsunami in the laboratory. This is providing the vital information needed to better characterize the forces imparted by tsunami inundation flows on coastal infrastructure, and has allowed the inclusion of the flow state in force equations presented in Section 2.0.

The time is now ripe for transferring this new knowledge on the physics of tsunami inundation flows into the field of structural engineering, so as to develop new approaches and guidance for the design and assessment of coastal infrastructure for this hazard. Towards this goal, a new variable height pushover approach (VHPO) for the assessment of building response under tsunami inundation flows has been proposed and has been found to be highly promising.

It is shown that due to the long duration of tsunami inundation flows, large lateral loads can be applied to the structure for a relatively long duration. Due to this long duration and limits to the ductility supply of structures, if these tsunami loads exceed the lateral strength of the structure it is likely to collapse. In tsunami design this observation would translate into the elastic design of structures for tsunami loading. However, this design concept conflicts directly with the use of ductile design in the seismic load case.

How do we reconcile these in cases when a building is at risk from both earthquakes and tsunami?

Fortunately, as seen in Section 5.0, due to the different loading characteristics of earthquakes and tsunami, major differences in the lateral load resistance of a structure can be achieved under the two load cases. For example, in the case study building, a much higher lateral strength can be achieved under the tsunami loading than under the earthquake loading. Section 3.0 suggests that a particularly high lateral strength might be achieved in the structure if its vertical elements are designed such that they can resist the high shear loads imposed by a tsunami at the building's lower storeys. For this case, seismic detailing for shear can help, but might have to be extended to the entire member rather than solely at element critical sections defined through earthquake loading considerations. However, this recommendation needs to be informed by further studies.

But what is the effect of preceding earthquake damage on the tsunami strength of buildings? According to the analyses run by Rossetto et al. (2018b) on the Japanese tsunami evacuation structure, the effect of the earthquake damage on the tsunami strength is very limited unless the earthquake damage is extensive or has induced partial collapse. This is encouraging for the design of buildings under 
earthquake and tsunami loading. However, these findings are based on a limited number of analyses carried out on a special structure, and throughout the Chapter gross assumptions have been made in neglecting tsunami inundation forces associated with buoyancy and debris impact. Hence, significant work remains to be carried out to advance the field of tsunami engineering.

\section{Acknowledgements}

The research presented in this Chapter has been predominantly funded by the European Research Council under the European Union's Seventh Framework Programme (FP7/2007-2013)/ERC grant agreement number 336084 'URBANWAVES', awarded to Professor Tiziana Rossetto. The authors are grateful to Dr. David McGovern, Dr. Ian Chandler, Professor William Allsop, Dr Tristan Robinson and Dr Christian Klettner for their assistance in this research

\section{References}

Allsop, W., Chandler, I., Zaccaria, M. (2014). Improvements in the physical modelling of tsunamis and their effects. In: Coastlab14 (5th International Conference on the Application of Physical Modelling in Coastal and Port Engineering and Science), 29 September - 2 October 2014, Varna, Bulgaria. (2014) ASCE 7-16 (2017). ASCE 7 standard Minimum Design Loads and Associated Criteria for Buildings 488 and Other Structures.

Attary, N., van de Lindt, J. W., Unnikrishnan, V. U., Barbosa, A. R., Cox, D. T. (2017) 'Methodology for Development of Physics-Based Tsunami Fragilities', Journal of Structural Engineering, 143(5).

Chandler, I., Allsop, W., Barranco Granged, I., McGovern, D. (2016) Understanding wave generation in pneumatic tsunami simulators. In: Coastlab16 (6th International Conference on the Application of Physical Modelling in Coastal and Port Engineering and Science), 10-13 May 2016, Ottawa, Canada. (2016)

FEMA (2000) FEMA 356. Prestandard and Commentary for the Seismic Rehabilitation of Buildings. Washington.

FEMA (2005). Coastal Construction Manual, third edition. FEMA 55, Federal Emergency Management Agency, Washington D.C.

FEMA (2008). Guidelines for Design of Structures for Vertical Evacuation from Tsunamis. Technical Report P646, Federal Emergency Management Agency, Washington D.C.

Foster, A. S. J., Rossetto, T. and Allsop, W. (2017) 'An experimentally validated approach for evaluating tsunami inundation forces on rectangular buildings', Coastal Engineering. The Authors, 128(November 2016), pp. 44-57. doi: 10.1016/j.coastaleng.2017.07.006.

Goda, K., Petrone, C., De Risi, R., Rossetto, T. (2017) 'Stochastic coupled simulation of strong motion and tsunami for the 2011 Tohoku, Japan earthquake', Stochastic Environmental Research and Risk Assessment. Springer Berlin Heidelberg, (November), pp. 1-19. doi: 10.1007/s00477-016-1352-1. 
Grilli ST, Ioualalen M, Asavanant J, Shi F, Kirby JT, Watts P. (2007). 'Source constraints and model simulation of the December 26, 2004, Indian Ocean Tsunami'. Journal of Waterway, Port, Coastal and Ocean Engineering. 133:414-428.

Latcharote, P. and Kai, Y. (2014) 'Nonlinear Structural Analysis of Reinforced Concrete Buildings Suffering Damage from Earthquake and Subsequent Tsunami', in 10th U.S. National Conference on Earthquake Engineering - Frontiers of Earthquake Engineering.

Mader CL. (2004). Numerical Modeling of Water Waves. 2nd ed. London: CRC Press; 2004.

Okada, T., Ishikawa, T., Tateno, T., Sugano, T., Takai, S. (2006). Tsunami loads and structural design of tsunami refuge buildings. Technical report, The Building Centre of Japan.

Park S, van de Lindt JW, Cox D, Gupta R, Aguiniga F. (2012). Successive earthquake-tsunami analysis to develop collapse fragilities. Journal of Earthquake Engineering;16(6):851-63.

Petrone, C., Rossetto, T. and Goda, K. (2017) 'Fragility assessment of a RC structure under tsunami actions via nonlinear static and dynamic analyses', Engineering Structures. The Authors, 136, pp. 36-53. doi: 10.1016/j.engstruct.2017.01.013.

Qi, Z. X., Eames, I. and Johnson, E. R. (2014) 'Force acting on a square cylinder fixed in a free-surface channel flow', Journal of Fluid Mechanics, 756, pp. 716727. doi: 10.1017/jfm.2014.455.

Rossetto, T., Allsop, W., Charvet, I., Robinson, D. I. (2011). 'Physical modelling of tsunami using a new pneumatic wave generator'. Coastal Engineering 58(6), 517527.

Rossetto T, Gehl P, Minas S, Galasso C, Duffour P, Douglas J, Cook O.(2016). 'FRACAS: A capacity spectrum approach for seismic fragility assessment including record-to-record variability'. Engineering Structures. 2016 Oct 15;125:337-48..

Rossetto, T., De La Barra, C., Petrone, C., De La Llera, J.C. (2018a) 'Comparison of Nonlinear Static and Dynamic Analysis Methods for Assessing Structural Response Under Earthquake and Tsunami in Sequence', Earthquake Engineering and Structural Dynamics (submitted).

Rossetto, T., Macabuag, J., Petrone, C. and Eames, I. (2018b) 'Does Ductility Play a Significant Role in the Response of Structures to Tsunami Loading?', Earthquake Spectra, (under review).

Rossetto T, Peiris N, Pomonis A, Wilkinson SM, Del Re D, Koo R, Gallocher S. (2007). 'The Indian Ocean tsunami of December 26, 2004: observations in Sri Lanka and Thailand'. Natural Hazards; 42(1):105-24.

Sundermann, L., Schelske, O., Hausmann, P. (2014). Mind the risk - A global ranking of cities under threat from natural disaster'. Swiss Re. Report No. 1505715_13_en12/14.pp.39.

Suppasri, A., Latcharote, P., Bricker, J.D., Leelawat, N., Hayashi, A., Yamashita, K., Makinoshima, F., Roeber, V., Imamura, F. (2016) 'Improvement of Tsunami Countermeasures Based on Lessons from The 2011 Great East Japan Earthquake 
and Tsunami - Situation After Five Years', Coastal Engineering Journal, 58(4), p. 1640011. doi: 10.1142/S0578563416400118.

Titov V.V., Synolakis, C. E. (1998). 'Numerical modeling of tidal wave runup'. Journal of Waterway, Port, Coastal and Ocean Engineering. 1998; 124:157-171.

Yepes-Estrada, C., Silva, V., Rossetto, T., D'Ayala, D., Ioannou, I., Meslem, A. and Crowley, H. (2016). The Global Earthquake Model Physical Vulnerability Database. Earthquake Spectra, 32(4), pp.2567-2585. 